\title{
IMAGINES ROMANAE: CULTURA E PODER ${ }^{*}$
}

\author{
IMAGINES ROMANAE: CULTURE AND POWER
}

Paulo Martins**

paulomar@usp.br

RESUMO: Este artigo tem a finalidade de propor uma reflexão inicial sobre a cultura imagética romana e sua veiculação na sociedade romana (52 a.C. - 132 d.C.) e, na nossa, tendo em vista sua constante exploração e fruição em museus e em exposições. Assim, nosso trabalho observa como a cultura material da Antiguidade romana tanto nos últimos 50 anos da República, como nos primeiros 130 anos do Principado pode ser lido e fruído de forma diversa hoje em dia. Tal reflexão na verdade está ligada a uma questão que nos parece central e seminal: há uma cultura imperial? Isto é, em que medida podemos dizer que existe uma única cultura imperial que atenda ao conjunto de diversidades impostas não só pelo recorte temporal que está contido na ideia de imperial, como também pela diversidade das populações que se subordinam ao centro do poder de Roma no decorrer dos anos? A segunda questão que se impõe hoje é se conseguimos dar conta das significações à época de sua produção, ou simplesmente operamos de maneira sistêmica outras traduções possíveis a essas imagens com nossos olhos contemporâneos.

PALAVRAS-CHAVE: Roma; imagens; público; privado; exposições; cultura.

\footnotetext{
* Este texto foi parcialmente apresentado no Colóquio Internacional "O Império Romano e suas províncias: integração e seus limites”. Museu de Arte de São Paulo (MASP) e do Laboratório de Estudos sobre o Império Romano/Mediterrâneo Antigo (LEIR/MA) em 29 de Março de 2012, por ocasião da "Exposição Roma: a vida e os imperadores". Agradeço ao Prof. Dr. Carlos Machado o convite para o Colóquio e aos pareceristas anônimos de $H R$ as sugestões.

** Doutor em Letras Clássicas. Professor de Língua e Literatura Latina da Faculdade de Filosofia, Letras e Ciências Humanas da Universidade de São Paulo.
} 
ABSTRACT: This paper aims to propose an initial reflection on the image culture and its propagation in Roman society (52 BC - $132 \mathrm{AD}$ ), and its contemporary constant exploration and fruition in museums and exhibitions. Thus, our study observes how the material culture of Ancient Rome both in the last 50 years of the Republic as in the first 130 years of the Principate can be read in diverse forms and brought to fruition today. Such reflection is actually linked to a question that seems central and seminal: is there an imperial culture? That is, to what extent can we say that there is only one imperial culture that meets the set of diversities imposed not only by time frame that is contained in the idea of imperial, as well as the diversity of populations that are subordinated to the centre of power in Rome over the years? The second question to be answered now is whether it is possible to grasp all the meanings at the time of its production, or if we simply operate, in a systemic manner, the translations of these images that our contemporary eyes make possible.

KEYWORDS: Rome; images; public, private; expositions; culture.

Tem este texto a finalidade de propor uma reflexão sobre a cultura imagética romana e sua veiculação naquela sociedade 52 a.C. - 132 d.C.) e, na nossa, tendo em vista sua constante exploração e fruição em museus e em exposições. Tal reflexão, na verdade, está ligada a uma questão que me parece central e seminal: há uma cultura imperial? Isto é, em que medida podemos dizer que existe uma única cultura imperial que atenda ao conjunto de diversidades impostas não só pelo recorte temporal que está contido na ideia de imperial, como também pela diversidade das populações que se subordinam ao centro do poder de Roma no decorrer dos anos? Outra questão que se impõe hoje é se conseguimos dar conta das significações à época de sua produção, ou simplesmente operamos de maneira sistêmica outras traduções possíveis a essas imagens com nossos olhos contemporâneos. Ou mesmo, se há esta cultura imperial, este grande 
implícito, teríamos nós hoje condições de lê-la com os mesmos olhos daqueles que a construíram e a fruíram?

Entretanto, antes de explorarmos o cerne do trabalho, faço aqui um pequeno excurso e lembro inicialmente um dado instigante: a sequência de três exposições sobre Roma nos últimos anos em três cidades distintas, Londres, Roma e São Paulo. Por ser repetitivo, parece-me instaurador de uma série, que para nós, que tentamos estudar ou as antiguidades, ou as ruínas, ou a morte, ou esses três temas, é algo sempre valioso; afinal uma série, seja qual for, atende a uma demanda, ou pelo menos sinaliza para uma expectativa de seus agentes e/ou de seus pacientes. Entretanto, longe de nós, virmos a imaginar que elas, a expectativa ou a demanda, sejam as de mercado. Mas, se não são de mercado, do que seriam? Tentemos entendê-las. De Certeau (1982, p. 46) em $A$ Escrita da História propusera, nesse sentido: "fundada sobre corte entre um passado que é seu objeto, e um presente, que é o lugar de sua prática, a história não para de encontrar o presente em seu objeto, e o passado, em suas práticas." Assim a demanda ou a expectativa a que me refiro parecem ser justamente este corte apontado por De Certeau que imiscui o passado e o presente.

Em 2008, o Museu Britânico propôs uma exposição cujo nome era Hadrian: Empire and Conflict. ${ }^{1}$ Seus organizadores indicavam à época que aquela exposição observaria para além de uma imagem criada de Adriano. Mais do que isso, ela iria oferecer novas perspectivas sobre sua vida e seu legado, explorando as grandes contradições da sua personalidade e seu papel como um comandante militar implacável (OPPER, 2008). Parece-me que o conflito a que se refere o nome da exposição é justamente a relação entre o poder político inegável de Adriano e sua vida privada, mormente a parcela da intimidade, decalcada em sua relação estreita com Antínuo. Parece-me, porém, que o dito conflito é uma construção extemporânea e anacrônica, pois é construído de acordo com os critérios morais de nosso século e, mais, da sociedade britânica. Logo, se 
é esta a ideia de conflito que está proposta pelo nome da exposição, os próprios organizadores, em material auxiliar produzido aos professores, fizeram uma indicação que aponta não para um conflito, mas para uma completa conciliação entre a relação mantida com Antínuo e as investiduras políticas de Adriano (potestas ou auctoritas):

A vida privada de Adriano tem sido assunto de alguns comentários e intrigas. Ele era abertamente homossexual que dava pouca importância aos romanos comuns. Seu amor, Antínuo, era um jovem grego da entourage de Adriano. Ele morreu em 130 d.C. no Nilo, por razões, até hoje desconhecidas.

O que o torna tão significativo foi a reação de Adriano diante de sua morte. A fim de superar seu luto, Adriano cercou-se de imagens de Antínuo - pelo menos dez sozinhas foram encontradas no Tívoli. Ele esbanjou honras póstumas sobre ele, incluindo aí a deificação. $O$ povo do Egito foi encorajado a venerar Antínuo como uma encarnação de Osíris. Adriano fundou Antinópolis (cidade de Antínuo), uma cidade próxima de onde ele tinha morrido.

A imagem de Antínuo tornou-se um ícone cultural no Império, especialmente para os gregos, mas o culto de Antínuo, espalhando-se atingiu lugares mais distantes. Por exemplo, taças com sua figuração foram encontradas na tumba de um governador na atual Geórgia. (THE BRITISH MUSEUM, 2008).

Assim, apesar de um desatino em relação à ideia de conflito, a exposição demonstrou interseções possíveis entre o público e o privado, a despeito de deter-se quase exclusivamente na imagem do grande imperador romano. O que ocorre com o modelo Antínuo (Figuras 1, 2 e 3) parece iluminar uma questão de base nas representações romanas, qual seja, a possível migração da imagem privada para o âmbito público. Assim, apesar de haver grandes diferenças de estilo entre a figuração privada e a pública, muita vez é observada a transposição do privado para o público, ou melhor, não que observemos uma alteração do modo figurativo, mas a migração do uso de seu referente, como é o caso de Antínuo, que sai de sua 
esfera privada em relação à Adriano e passa a ser figurado nos confins do Império em esfera pública, sob a rubrica do poder público de Adriano.

Dessa maneira, a figuração de Antínuo a que se refere essa passagem do material produzido para professores dessa exposição é tipicamente pública, o que nos leva a matizar e relativizar os conceitos de figuração hoje em voga na História da Arte Antiga. Explico. Se o referente de Antínuo traz em si mesmo a indicação ou informação de sua relação homossexual com Adriano, esta referência não é outra que não uma referência privada, porém o modelo de figuração e sua exposição é essencialmente pública, haja vista a carga ou a nota de marcas de figuração em chave idealizada, um simulacrum. Na verdade, não há à disposição imagens privadas de Antínuo. Seguem algumas possibilidades:

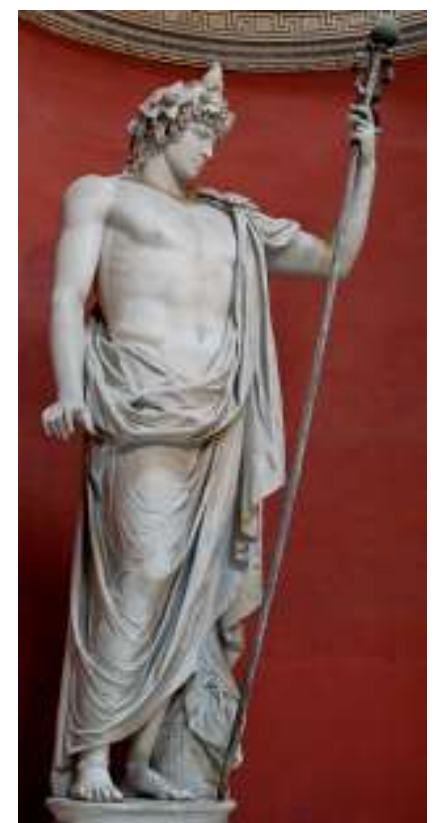

Figura 1: Antínuo como Baco do Museu Pio-Clementino, Museus do Vaticano Inv.: $256^{2}$ 


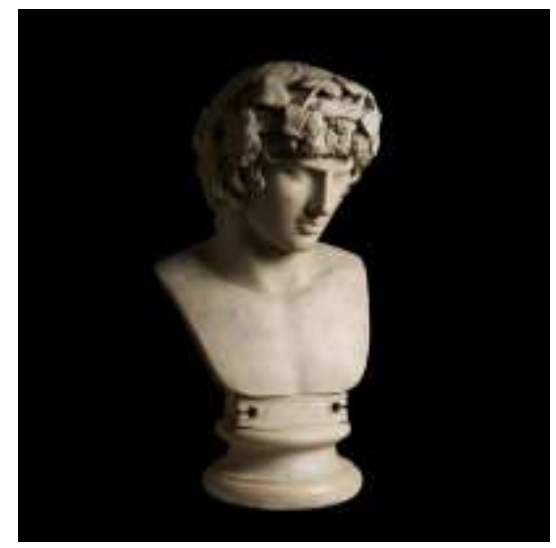

Figura 2: Antínuo do Museu Britânico, Londres Inv: GR $1805^{3}$

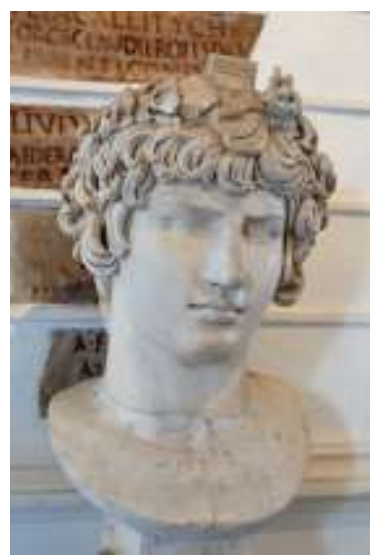

Figura 3: Antínuo dos Museus Capitolinos, Roma ${ }^{4}$

No final de 2011, os Museus Capitolinos de Roma (Palazzo dei Conservatori e Palazzo Nuovo) propuseram uma exposição chamada Ritratti. Le tante facce del poter ${ }^{5}$. Nela estavam expostas imagens romanas representativas de todas as vertentes de figuração do retrato romano, sejam elas privadas, sejam públicas, pensando aqui a distinção levada a termo por Bandinelli, há alguns anos, no seu trabalho, hoje um clássico, Roma: L'arte romana nel centro del potere. Ou mesmo, a consecução histórica desse trabalho, escrita por Paul Zanker, The power of images in the age of Augustus. A finalidade da exposição tornava-se nítida logo na entrada da primeira sala, já que lado a lado e frente a frente estavam dispostos vários estilos distintos de retrato: um ligado às máscaras mortuárias, outro associado à elevação divina dos representados, outro à exposição cotidiana pública de certos nomes importantes da política romana, ou um outro ligado à fruição cotidiana de um anonimato para nós 
e, quem sabe, até para eles romanos. Aquela curadoria, portanto, centrou sua atenção na mesma tensão - público versus privado - que acabamos de salientar na mostra do Museu Britânico, mas agora sob outra perspectiva, já que não soldada a um só personagem, no caso, Adriano, mas sim à totalidade de possibilidades figurativas, haja vista a larga gama de matizes de representação e a amplitude de referentes. Dividiam o espaço dos Museus imperadores e homens anônimos; mulheres figuradas divinizadas ou em sua estatura sócio-religiosa própria.

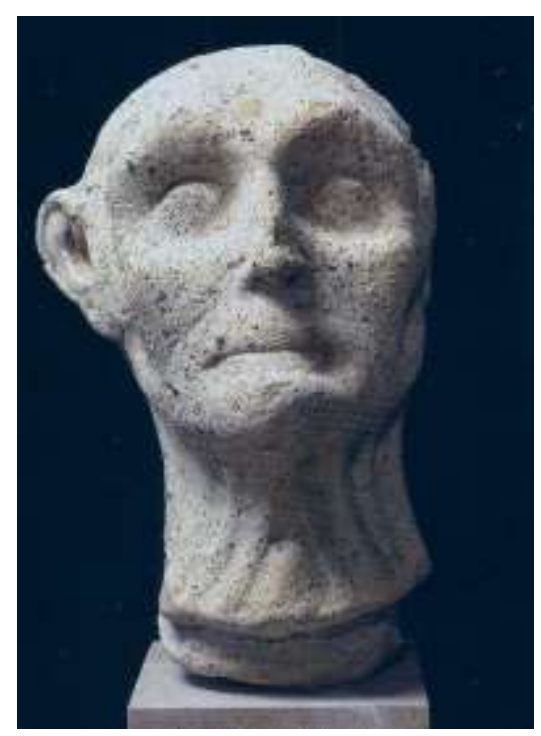

Figura 4: Cabeça de Argila - Museu do Louvre, Paris - Inv: $848^{6}$

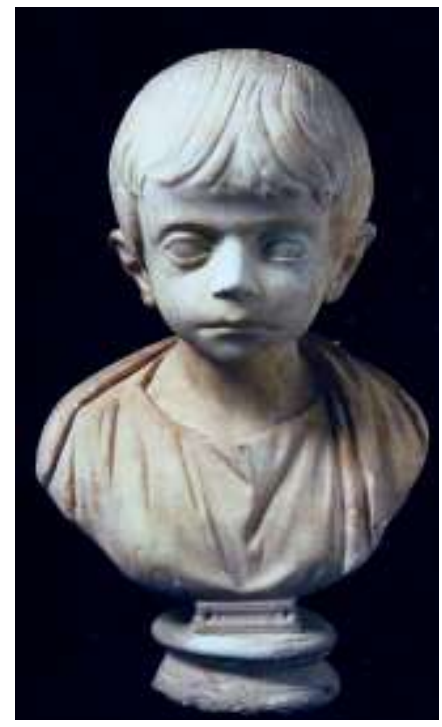

Figura 5: Busto infantil - Museus Capitolinos, Roma - Palazzo Nuovo Inv: $3520^{7}$

Essas duas peças, apresentadas nesta exposição (Roma, 2011), trabalham duas dimensões do privado, diferindo apenas o nível de especificidade técnica de cada delas. Ambas apontam para o momento da 
morte. A primeira (Figura 4) em argila remete ao momento posterior à mascara de cera que era feita no momento da morte. Tal peça, a que M. Papini (2011) atribui um "realismo brutal" ou ainda "sem sofisticação formal", caracteriza-se pela reverência aos antepassados cuja função estava associada a dois momentos distintos da vida romana: o primeiro relativo a sua própria conservação na domus, nos columbaria, nos atria para observação e fruição cotidiana dos membros da família como exemplum do mos maiorum e o segundo momento nos funera gentilicia $^{8}$, momento em as máscaras dos ancestrais carregadas por membros da gens, abandonando o atrium, eram levadas em procissão ao forum. A segunda (Figura 5) um mármore produzido a partir de um molde anterior em barro, provavelmente, ocupa o espaço do páthos, do sentimento, da consternação, afinal o menino morto não pode ser exemplum de uirtus, entretanto igualmente oferece à família e, mesmo, à sociedade alguma função no post mortem. 


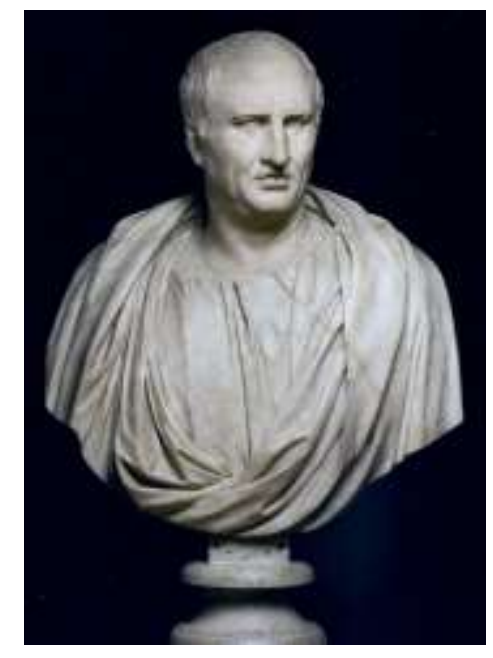

Figura 6: Busto de Cícero - Museus Capitolinos, Roma - Inv.: $589^{9}$

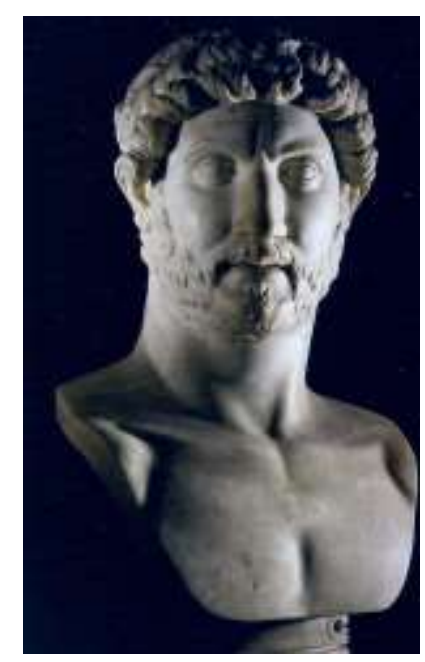

Figura 7: Busto de Adriano - Museu Pio-Clementino, Vaticano - Inv.: $724^{10}$

Nessas duas peças, ainda referentes à exposição romana, podemos observar dois tipos interessantes de figuração pública. A verista de origem republicana: uma effigies de Cícero (Figura 6) cuja sisudez e austeridade parece-nos representativa de suas posições políticas. A panagem da toga e sua expressão physiognomica refletem sua filiação ao verismo e distinguem-se por um anseio de propagação da imagem da seriedade do modelo de República a que se filia. Por seu turno, o Busto de Adriano (Figura 7), um simulacrum ${ }^{11}$, distingue-se pela idealização, afastando-se do modelo, e aproximando-se das figurações divinas ou heroicas, em que se nota uma sobriedade sobre-humana. Tal representação parece-me associada também a modelos helênicos.

No início de 2012, assistimos, com nossos olhos brasileiros, a uma exposição, que, senão centrada no poder romano, pelo menos muito próxima daquilo que os romanos viam de si, desde seus utensílios insignificantes (isso, para os imprudentes) a imagens significativas de seu 
poder contaminador em seu valor, digamos, cultural, a despeito do que este termo "cultura", deslocado de sua significação estrita e estreitamente esclarecida, possa significar. Dois bons exemplos são os retratos de Júlio César (Figura 8), exemplar de sua majestade colossal, e ao mesmo tempo, cúmplice de anseios populares, logo como apresentação assinatura da mostra e um Cícero (Figura 9) prototípico cuja seriedade e sisudez apontam para um êthos, absolutamente, pré-discursivo, tão necessário ao orador e ao político romano republicano. Esta exposição que se nos apresentou o Museu de Arte de São Paulo/MASP, então, foi talvez uma das experiências mais profícuas para os Estudos Clássicos, nestes trópicos tão tristes, com todo o perdão de Lévi-Strauss.

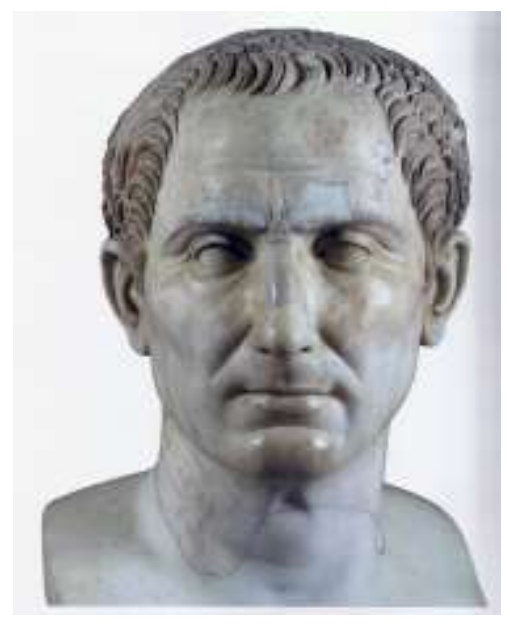

Figura 8: Júlio César Colossal - Museu Arqueológico Nacional de Nápoles - Inv.: $6038^{12}$

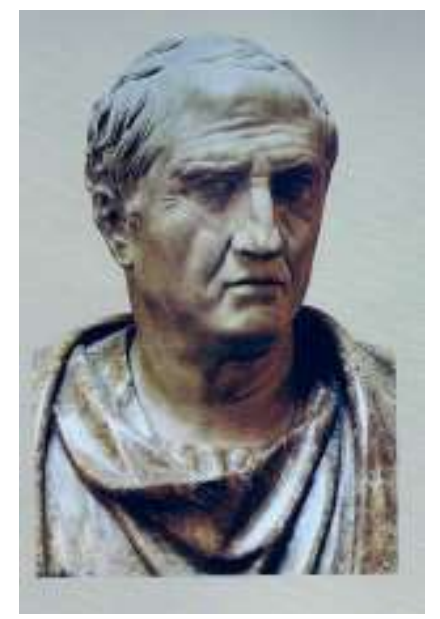

Figura 9: Cícero - Galleria degli Uffizi de Florença Inv: $352^{13}$ 
Assim, Roma - A Vida e os Imperadores ${ }^{14}$ além de observar o que são as imagens dos imperadores e quais são os resultados de suas exposições na maneira de pensar (forma mentis) de um romano (urbano ou provinciano) imerso nesse universo, também re-contextualiza estas imagens em acordo com vida cotidiana de seus modelos e de seus expectadores, orientando-nos dentro da sociedade romana, conforme suas visadas e necessidades. Assim também se recuperou a dicotomia ou tensão já salientada entre o público e o privado, entretanto, neste caso é visível a prudente seleção de peças. Os curadores inserem o Imperator dentro do universo comum da vida citadina e cotidiana romana. Sua magnificência figurativa contrasta com lamparinas, com vasos, com urnas, com estilos, com fivelas, adornos e utensílios, sem os quais, apesar das majestades, não poderiam sobreviver em Roma. Ao mesmo tempo, a vida privada de personagens anônimos se apresentava diante dos homens públicos ainda que apenas depois da sua própria morte.

Desta via de mão dupla creio emanar uma relação de poder. Destes anônimos, na maioria das vezes, figurados privadamente, vê-se a replicação das imagens dos imperadores em si mesmos como que amparando seu poder. Detecta-se, assim, a partir destas imagens de personae, em pleno exercício do anonimato, sua adesão a um sistema de poder, que, de acordo com Foucault (1996, p. 182) em sua Microfísica do Poder, sempre ocorre em rede e de baixo para cima, isto é, o poder emana da capilaridade social que o comporta.

Bem, parece certo que, a partir destes três exemplos, Roma e seus efeitos, sejam eles privados, sejam públicos, afetam de alguma forma aqueles que pensam cultura vigente hoje neste mundo pós-estruturalista, ou melhor, neste mundo, pós-tudo, uma vez que três grandes museus assumem para si a tarefa grandiosa de tentar fazer com que as pessoas no século 21 percebam quais os limites e possibilidades que esta civilização impôs-se a si mesma e quais contributos oferece aos dias de hoje como forma de pensar e de agir. 
Tais contribuições, entretanto, é sempre bom lembrar, não são imunes a todo mal ou a todo bem, já que o reflexo do universo romano foi lido muitas vezes em foco distorcido e embaçado, produzindo, digamos, anomalias históricas - não, ou talvez sim, condizentes com a natureza humana e das quais a civilização ocidental não deve se orgulhar. Penso aqui na reutilização dos moldes romanos em bases extemporâneas, plenas de fascismo de Mussolini, ou do inominável nacional-socialismo da Alemanha entre Guerras. Porém, na mesma medida, há o legado antagônico a esse: o de valorização de virtudes, matizadas pelo tempo, e lógico, das quais não devemos, em momento algum, nos distanciar e destas últimas, ao que parece, trata esta e as demais exposições sobre a Arte Romana. Esta é minha tarefa: observar imagens romanas e associá-las ao poder, procurando um sentido, um fim para elas, lá e cá.

Voltando ao tema provocador que na verdade era a indagação "há uma cultura romana?", de partida, digo que, a rigor, a união entre o substantivo cultura e o adjetivo imperial que o restringe e o qualifica é perigosa, sob uma perspectiva histórica, afinal o que seria esta "cultura" para os romanos do império e ainda qual "imperial" é este? Outra questão se coloca: a quem se destina a observação desta cultura imperial?

Bem, se pensarmos que são os romanos, seguramente 0 questionamento será inócuo, dado que cultura para eles, apesar da expressão metafórica, cunhada por Cícero em'As Tusculanas - cultura animi -, se ligava exclusivamente à agricultura como até hoje sobrevive no vernáculo, ainda que como entrada secundária nos dicionários. E o termo imperialis, para eles, seria relativo à investidura do imperium, atribuída aos generais em campanha fora de Roma, sentido que nos é inexistente em bom português. Assim a união entre os termos em latim, redundando na expressão cultura imperialis ${ }^{15}$, ao que parece, soaria sem nexo, pelo simples 
motivo que ambos conceitos se referiam a significados distantes de seus referentes hoje em dia.

Entretanto, sob o nosso ponto de vista, nos colocando na posição de referente e alvo necessário, podemos, talvez, concordar com a existência e razoabilidade da expressão, haja vista, por exemplo, a obra de Karl Galinsky (1996) - Augustan culture: an interpretative introduction que sintetiza em certa medida e em outra, responde à questão proposta, já que a pressupõe uma "cultura augustana" como existente. Mas mesmo assim devemos estreitar e limitar a expressão.

No que se refere ao substantivo "cultura" devo supor que estamos a entendendo em seu senso comum? Ou devo supor a proposição de Saussure, revitalizada por Lévi-Strauss(1958; 1962) e por Jakobson? Respondo de pronto que prefiro esta àquela. Assim, a cultura é basicamente um sistema de signos produzidos pela atividade simbólica da mente humana e, dessa maneira, ela é também uma mensagem que pode ser decodificada tanto em seus conteúdos, como em suas regras. Posso, portanto, nesse viés, dizer que a cultura é efetivamente o produto ou a soma de produtos da capacidade simbólica da mente humana que se resume no arranjo das coisas do mundo em grupos aos quais são concedidas cargas semânticas. Assim, parece-me fundamental esclarecer as regras que estão na base da articulação entre os símbolos numa cultura, clarificando a forma como estes proveem de sentido a atuação de uma sociedade.

Por sua vez, o termo "imperial" nunca me soou agradável ou preciso, pelo menos pensando em Otávio Augusto, mas a pressupor o uso comum temporal como adjetivação concernente ao período romano posterior ao II triunvirato, instaurado por Otávio a partir do consenso do Senado pode ser razoável. Ainda assim o termo criaria um monstro, pois colocaria lado a lado coisas e eventos inconciliáveis, por exemplo, o principado de Otávio dista muito de outros principados tardios de Roma, uma vez que os poderes, as culturas, enfim, as mentes são outros e de 
outros que não os mesmos. Hoje, portanto, acho prudente delimitar temporalmente o termo "imperial" e, observarei, do inicio do principado de Augusto até os últimos dias do principado de Adriano (dinastia flaviana).

Posso, então, dizer que este texto já apresenta fios que ficaram soltos para trás e que talvez seja importante retomar esquematicamente, são eles: a) seu período e cerne: a cultura imperial júlio-claudiana e flaviana; b) seu corpus: as imagens do período; c) preocupação: a relevância desta produção cultural hoje; d) finalidade: o que depreendemos dela.

A partir do final da República assiste-se em Roma à consolidação da produção de effigies, simulacra, statuae... entendendo cada uma destas modalidades como reverenciadores de modos de representação que são emulados e que, de forma geral, resumem-se aos conceitos de imagines em Roma ou, de eikónes (MARTINS; AMATO, 2012, p. 125-158) na Grécia. Tais representações operavam plasticamente, ao que me parece, quatro modelos: o helênico, o helenístico, o médio-itálico e o romano. Não que outros matizes da figura (fingere, fictus) não circulassem. Penso, por exemplo, em modelos etruscos, egípcios e assírios que se não aparecem em estado, digamos, puro, ora estão "contaminando" as imagines, ora as imagines os emulam, ora se fundem às imagines e, assim, estas figuras são fruídas em Roma no período, bons exemplos são as figurações de Antínuo como Osíris (Figuras 10 e 11): 


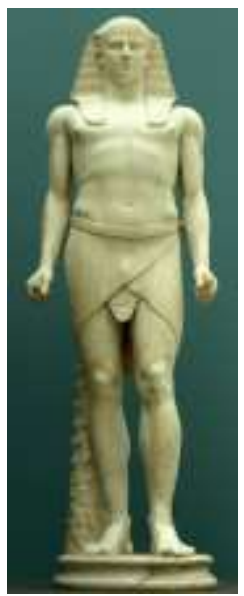

Figura 10: Antínuo-Osíris - Museu Gregoriano, Museus do Vaticano. Inv.: $22795^{16}$

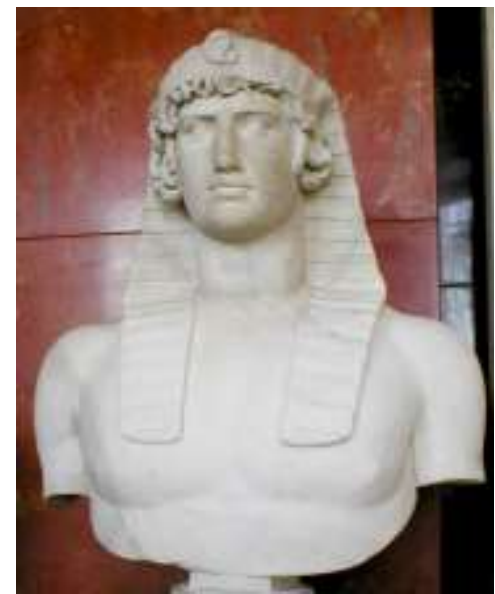

Figura 11: Busto de Antínuo-Osíris - Museu do Louvre, Paris - Inv.: Ma 433 (MR 16)

Sob outro aspecto, digamos, sob a estilização destas imagens, duas características devem ser postas em evidência: aquela que se apega ao forum, ao templum, portanto, ao público e aquele que se atém a casa, ao atrium, ao columbarium, à domus, logo, ao privado, não que não houvesse na domus espaços públicos, pois haviam, como adverte o trabalho de Thebért (1993). Quando proponho estilização, não falo do conceito romântico de estilo, antes me refiro à intencionalidade retórica do decorum.

Se imaginarmos que ambas as categorias, as de estilo e as de modelo se entrecruzam e se complementam, podemos, em certa medida, sintetizar possibilidades de figuração no período. Bem, se todas elas convivem, e tudo está sob o controle de um artista que a produz e de uma clientela que a consome ou frui. Quais as motivações que o leva a adotar um tipo de figuração? O acaso seguramente não é! Proponho que seja o 
tempo e a necessidade de dele extrair lições, daí serem importantes os modelos explorados nas três exposições.

Pode parecer uma leitura pueril esta, pois inicialmente grande parte daqueles que se dedique a estudar imagens, estilos, modelos e funções da figuração parte de um recorte temporal a fim de delimitar semelhanças e destacar diferenças entre seus objetos, produzindo uma taxonomia científica. Quando proponho o tempo, não o trato como base desta trans-historiedade, mas sim como elemento referencial da produção imagética. Explico.

O que me preocupa são as significações que estes signa visuais assumem, dependendo do tempo a que se referem para os romanos daquele recorte temporal a que me propus observar. As efígies funerárias, tão bem estudas pela professora Herriet Flower (1996), podem ser associadas, por exemplo, ao passado, já que os figurados são apresentados aos espectadores tais e quais em seu momento de morte - são modeladas a partir da cera (Figuras 4 e 5). O culto patrício destas imagens apresenta-se como um momento de rememorar a vida, ou melhor, de cultuar qualidades, virtudes vetustas da gens. O modelo dessas effigies aponta para os costumes passados, a relativização do tempo que se apresenta a partir da imagem é aquilo que o defunto foi para o grupo.

Assim, se imaginarmos que a cada morte todos os outros mortos da família eram conjuntamente relembrados nos funera gentilicia, haverá sempre uma amplificação por acúmulo das qualidades gentílicas a serviço, portanto, de uma estrutura de poder, referendada culturalmente. Afinal a cultura, como vimos, depende desse consenso do grupo social.

Bem, já se pensarmos em algumas imagens públicas de imperadores figurados como generais, aos moldes do Augusto da Prima Porta (Figura 12), hoje no Vaticano, ou ainda, como Pontífice Máximo, penso aqui, no Augusto da Via Labicana do Museu Nacional Romano - 
Palazio Massimo alle Terme, Roma (Figura 13), ou ainda, outro Augusto, agora togado como aquele que temos na Galleria Ufizzi (Figura 14), de Florença, estaremos observando três modelos de statuae/effigies que estão referenciadas pelo tempo presente, não que sejam construídas em acordo com a semelhança do figurado, mas porque significam, para estes romanos, as investiduras que estão ali propostas como presente para eles e para o figurado e, tem, como finalidade, a exposição deste conforme suas atribuições naquela atualidade, isto é, bélica, religiosa ou política, respectivamente.

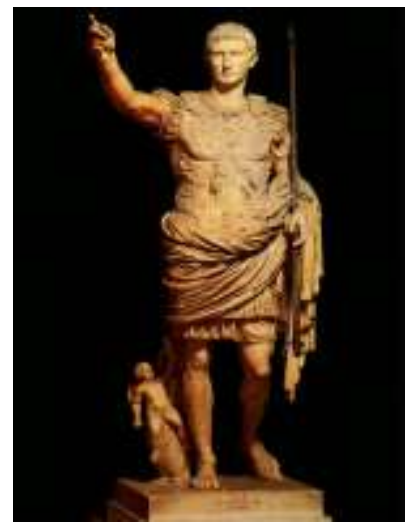

Figura 12: Augusto da Prima Porta - Museus do Vaticano

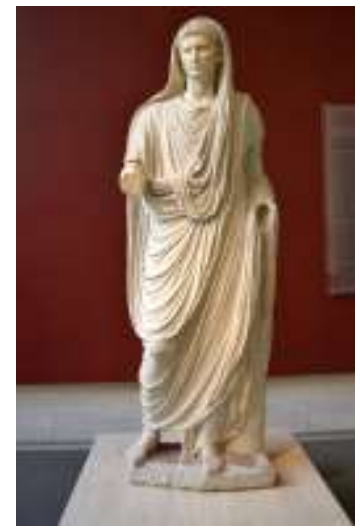

Figura 13: Augusto da Via Labicana - Pontifex Maximus - Museu Nacional Romano Palazio Massimo alle Terme

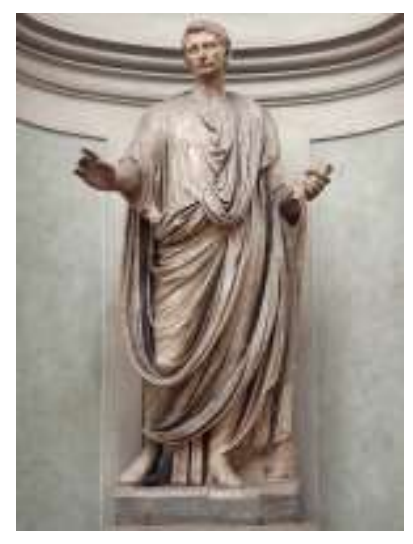

Figura 14: Augusto togado - Galleria degli Uffizi de Florença

Ao que parece o que nos resta é o tempo futuro, já que até mesmo o presente já se tornou passado. Ao contrário do que T. S. Eliot possa ter suposto, o futuro para esses romanos como para nós não 
pertencia ou pertence ao inexorável, antes estava e está absolutamente sob controle atento daquelas e destas mentes e olhos. Sim, os romanos e nós estavam (perdoem-me a silepse de pessoa) sempre preocupados com o futuro. Parece-me que, quando entregaram o futuro nas mãos de Deus, tudo se complicou para eles. Mas, claramente, eu disse Deus, não deuses, já que sempre estiveram lá muito próximos, tanto que até mesmo aqueles a quem tinham referendado o poder de príncipe, eram entendidos, divinos! Eram cultuados como se deuses fossem. Mas quando? Depois da morte quando ninguém mais pudesse lhes tirar tal atributo.

NOTAS

1 The British Museum. 24 July - 26 October 2008, exhibition curator Thorsten Opper.

${ }^{2}$ I, the copyright holder of this work, release this work into the public domain. This applies worldwide. In some countries this may not be legally possible; if so: I grant anyone the right to use this work for any purpose, without any conditions, unless such conditions are required by law. Disponível em $<$ http://en.wikipedia.org/wiki/Antinous>, acesso 17/06/2013.

${ }^{3}$ Copyright The British Museum. Disponível em $<$ http://www.britishmuseum.org/explore/highlights/highlight_objects/gr/b/bust_of_a ntinous.aspx> acesso em 17/06/2013.

${ }^{4}$ Disponível em <http://en.wikipedia.org/wiki/Antinous>, acesso 17/06/2013.

5 (Retratos. As Muitas faces do Poder). Ritratti. Le tante facce del potere. Musei Capitolini - Palazzo Caffarelli - Palazzo dei Conservatori. 10 Marzo - 23 Ottobre 2011. a cura di Eugenio La Rocca e Claudio Parisi Presicce. La seconda mostra del ciclo "I giorni di Roma" offre l'occasione di riflettere sul ritratto romano, vero e proprio strumento di comunicazione per affermare il prestigio politico e sociale in monumenti pubblici e celebrativi, monumenti funerari e nelle stesse dimore private a partire dalla tarda età repubblicana. 
Il ritratto è uno dei modi per tramandare la memoria di sé nel tempo. Attraverso le numerose tecniche artistiche adottate - pittura, scultura, fotografia e infine la più sconvolgente di tutte, la cinematografia, perché non congela la figura in un momento eterno, ma le dà una parvenza di mobilità e di vita - non muta il desiderio degli uomini di esorcizzare la morte lasciando ai posteri un'immagine di sé capace di sopravvivere nei secoli. La comparsa di un oggetto, non solo artistico, come sostituto dell'individuo è stata una delle prime azioni compiute dagli uomini, sia lasciando l'impronta delle proprie mani sulle pareti delle grotte, sia rivestendo i teschi degli antenati con argilla fino a dare loro un aspetto umano sia ancora erigendo sulle tombe segnacoli che ne dichiarino la presenza oltre la morte.

${ }^{6}$ LA ROCCA; PRESICCE; LO MONACO, p. 44.

${ }^{7}$ LA ROCCA; PRESICCE; LO MONACO, p. 48.

${ }^{8}$ Cf. MARTINS, 2011, p. 154-162; MARTINS, 2013, no prelo; FLOWER, 1996; NISTA, p. 33-39.

${ }^{9}$ LA ROCCA; PRESICCE; LO MONACO, p. 188.

${ }^{10}$ LA ROCCA; PRESICCE; LO MONACO, p. 329.

${ }^{11}$ Sobre a diferença entre effigies e simulacrum: MARTINS; AMATO, p. 140 e ss.

${ }^{12}$ CLEMENTE; LIVERANI, p.12.

${ }^{13}$ CLEMENTE; LIVERANI, p.112.

${ }^{14}$ Curador Guido Clemente.

${ }^{15}$ OXFORD LATIN DICTIONARY, 466 e OXFORD LATIN DICTIONARY, 3545

${ }^{16}$ Disponível em <http://en.wikipedia.org/wiki/Antinous>, acesso 17/06/2013.

${ }^{17}$ Disponível em <http://en.wikipedia.org/wiki/Antinous>, acesso 17/06/2013.

\section{REFERÊNCIAS}

BANDINELLI, R. B. Roma: L'arte romana nel centro del potere. Milano: Feltrinelli.1969. 
CLEMENTE, G.; LIVERANI, P. Roma. A vida e os imperadores. Catálogo da Exposição. Cagliari: Fabula. 2011.

DE CERTEAU, M. A Escrita da História. Rio de Janeiro: Forense. 1982.

FEDELI, P. La Poesia Politica degli Augustei. In: I. De Genaro and H-C. Gunther. Artists and Intellectuals and the Requests of Power. Leiden and Boston: Brill. 2009.

FLOWER, H. I. Ancestor Masks and Aristocratic Power in Roman Culture. Oxford: Clarendon Press. 1996.

FOUCAULT, M. Micofísica do Poder. Rio de Janeiro: Graal. 1996.

GALINSKY, K. Augustan Culture. An Interpretative Introduction. Princenton: Princenton University Press. 1999.

LA ROCCA, E.; PRESICCE, C. P.; LO MONACO, A. Ritratti. Le tante face del potere. Roma: MoMo. 2011.

LÉVI-STRAUSS, C. Anthropologie structurale. Paris: Plon. 1958.

LÉVI-STRAUSS, C. La Pensée Sauvage. Paris: Plon. 1962.

MARTINS, P. Imagem e Poder. Considerações sobre a representação de Otávio Augusto. São Paulo: Edusp. 2011.

MARTINS, P.; AMATO, R. S. S. Imagens antigas retoricamente referenciadas. In: MUHANA, A.; BAGOLIN, L. A.; LAUDANNA, M. (orgs.). Retórica. São Paulo: Annablume e IEB/USP: 125-158. 2012.

MARTINS, P. Os Romanos, as Imagens, o Direito e a Morte. In: FAVERSANI, F; JOLY, F. (org.). As Formas do Império Romano. Ouro Preto: Ed. UFOP. 2013. (no prelo).

NISTA, L. Ius imaginum and Public Portraiture. In: NISTA, L.; ANDERSON, M. Roman Portraits in Context. imperial and privete likeness from the Museo Nazionale Romano. Roma: De Luca Edizioni d'Arte. 1988. 
NODELMAN, S. (1993). How to Read a Roman Portrait. In: E. D'AMBRA. Roman Art in Context. An Anthology. New Jersey: Prentice Hall. p. 10-26.

OPPER, T. Hadrian: Empire and Conflict. London: The British Museum Press. 2008.

OXFORD LATIN DICTIONARY. Ed. P. G. W. Glare. Oxford: At Clarendon Press. 2006.

PAPINI, M. Le (Brutte) Cere dei Romani. Verità - senza bellezza - nella ritrattistica republicana. In: LA ROCCA, E.; PRESICCE, C. P.; LO MONACO, A. Ritratti. Le tante face del potere. Roma: MoMo. 2011.

THÉBERT, Y. Private and Public Spaces: The Components of the Domus. In: E. D'Ambra, (ed.). Roman Art in Context: An Anthology. Englewood Cliffs, Prentice Hall: 213-37. 1993.

THE BRITISH MUSEUM (Inglaterra). Live, Love, Legacy. Hadrian, Empire and Conflict. Resources for Teachers. 2008. disponível em: <http://www.britishmuseum.org/pdf/Hadrian_TeachResource.pdf>. Acesso em 1/12/2012. (Tradução Nossa).

ZANKER, P. The power of images in the age of Augustus. Translated by Alan Shapiro. Ann Arbor: The University of Michigan Press.1988. 